\title{
Productivity: Time of Day, Day of WEEK, AND Morningness EfFEcts
}

\author{
Kristin Lee Sotak ${ }^{1}$, Tianna R. Moxley ${ }^{1}$, Samira Todd ${ }^{1}$, \\ Shannon Yearwood ${ }^{1}$, and Gregory 7. Privitera ${ }^{2}$
}

${ }^{1}$ SUNY Oswego, Department of Marketing and Management, School of Business, 7060 NY-104, Oswego, NY 13126. ${ }^{2}$ Saint Bonaventure University, Department of Psychology, $3261 \mathrm{~W}$ State St, St Bonaventure, NY 14778

Kristin Lee Sotak is a Professor of Management at SUNY Oswego, Gregory J. Privitera is a Professor of Psychology at St. Bonaventure University, and Tianna R. Moxley, Samira Todd, and Shannon Yearwood are students at SUNY Oswego.

Corresponding author: Kristin Lee Sotak, Department of Marketing and Management, School of Business, SUNY Oswego, 7060 Route 104 Oswego, NY 13126, USA. Phone: 607-341-3781. E-mail: kristin.sotak@oswego.edu

\begin{abstract}
Student productivity is thought to fluctuate based on factors that include days of the week and individual differences. The purpose of the present study is to examine the effects of personality, day
\end{abstract}


of week, time of day, and morningness/eveningness on productivity. To extend previous research, the present study evaluated productivity as well as the interactions between variables, thereby allowing for assessment of interaction effects. A survey research design was used in which daily surveys were administered five times a day $(9 \mathrm{am}-12 \mathrm{pm}, 12 \mathrm{pm}-3 \mathrm{pm}, 3 \mathrm{pm}-6 \mathrm{pm}, 6 \mathrm{pm}-9 \mathrm{pm}$, and 9pm-12am) for ten weekdays, Monday through Friday. Results show that productivity is lowest on Friday's and that this effect was independent of morningness (i.e., no interaction effect) at all times of day.

Keywords: Productivity, day of the week, time of day, morningness/eveningness, individual difference, day of the week, time of day, morningness/eveningness, individual difference.

DOI: https://dx.doi.org/10.15239/j.brcacadje.2020.08.01.ja04

\section{INTRODUCTION}

Productivity is a subject of interest for numerous purposes in the personal, academic, and work spheres of modern society. CEOs crunch numbers and develop ideas to improve profit, academic board advisors implement methods to improve attendance and grades, and students plan when and how to study to improve academic performance. This is an increasingly important factor nowadays, where we have more things to accomplish yet less time to do so, and productivity has never been more relevant for the modern-day student. In fact, academic performance is a major stressor for those enrolled in academic institutions. In recent years there has been a $30 \%$ rise in college students seeking counseling, $61 \%$ due to anxiety and $28 \%$ due specifically to academic performance (Winerman, 2017). One of the most talked about subjects in college is time management and effective studying (Jackson, 2009). Both of these factors are considered integral to student success. Many colleges not only offer tips for how to live productive student lives on their websites but also integrate time management skills into their freshman courses to minimize stress and 
maximize efficiency (Purdue University Global, 2018; “Time management tips,”2019).

Recently the United States has had to face a rather bleak statistic: while education costs may be rising, learning has stagnated, with no significant gain in literacy of 17-year-olds since 1971, and there has been a complete plateau of math skills since the 1990s (National Center for Education Statistics, 2013). This has led to a significant decrease in the United States' education sector, and the implications for future society are grim (Rothwell, 2016). Only about half of the population born in 1980 is economically better off than their parents. Compare this to the $90 \%$ born in 1940 and we conclude that there has been a $40 \%$ decrease in stability in one or two generations (Chetty, Grusky, Hell, Hendren, Manduca, \& Narang, 2016). As the economic and societal implications of these statistics loom over educational institutions, it may be time to consider the impact of productivity from not only an academically task-oriented perspective but from a learning perspective. Results from studies of student productivity may not only be used to improve our understanding of work quality and time efficiency in education but may be implemented in public policy to maximize the quality of learning. These real-world applications may just be the impetus to a complete restructuring of how we teach, learn, and retain information. They may not only greatly improve the quality of our educational institutions but may enhance the current prognosis of the nation's economic status and overall quality of life.

The focus of the current study is to investigate the effects of time of day, day of week, individual differences in morningness/eveningness, and the interaction of these variables on productivity. While there is a great deal of previous literature analyzing the effect of various factors on individual productivity, nearly all of these factors are tested independently of one another. The purpose of the current study is to not only establish the significance of the effect of these factors specifically on academic 
productivity but also to analyze the interaction between these various factors and fill in any gaps left by previous research.

\section{LiterATURE REVIEW}

\section{Day of the Week and Productivity}

Societal and cultural stereotypes concerning days of the week are commonplace and are an integral factor of our seven-day week. They give rise to sayings such as "Monday Blues" (negative emotions associated with Monday), "hump day" (half way through the work week), and TGIF (thank god it's Friday). Though these stereotypes are mainly a result of our social interactions and structure, they still have a major effect on our moods and productivity. Mondays are said to be emotional and productive "low points" of the week due to several factors such as recovering from weekend activities and the shift from pleasurable activities to demanding activities (Areni, 2008; Larsen \& Kasimatis, 1990).

In some instances, it has even been found that Monday's are a high-point for incivility in the workplace (Nicholson \& Griffin, 2017) and behavioral infractions committed by children in school (Challen, 2016). This suggests that negative moods are peaking on Mondays unanimously among age groups and that these negative moods are reducing productivity due to the conflicts that arise from the low affective states. Supporting this, it has been found that Mondays are the lowest days of productivity during the seven-day week (Bryson \& Forth, 2007). Other studies have suggested that, in addition to the emotional aspect of Monday's, they are the lowest productive days of the week due to the amount of work that is incoming and the time it takes for individuals to re-adjust to their routine after spending the weekend engaging in social activities. Fridays were also found to be low on the productivity scale as well, being the second least productive day of the week next to Monday due to focus being on nearing weekend activities rather than important, task-related activities at hand (Dresner, Yao \& Zhu, 2010). Students are likely to experience these same 
mood effects, whether or not they are members of the workforce, due to the similarities between the structure and functioning of academic institutions and labor institutions. We expect that these low affective states will result in low Monday and Friday productivity in students.

\section{Time of the Day and Productivity}

In addition to days of the week, the time of the day has equally important effects on productivity. The implications of this factor are hard-hitting, especially taking into account the fact that the majority of secondary educational schedules in the United States start before 8:30 am (Center for Disease Control, 2015), which vehemently disregards the American Academy of Pediatrics (AAP) recommendation that middle schools and high schools should start no earlier than 8:30 am (Owens, 2014.) Contrary to the AAP's rulings, however, productivity and learning have been found to improve earlier in the day, with specific course GPAs improving when they are moved to earlier class times (Pope, 2016). It should be noted that in Pope's (2016) study gender, education of parents, age, and regular performance of the students were taken into account, but that the morningness/eveningness of the student or teachers were not tested for. Therefore, it has not been cited whether or not the students tested were of morning type, which could have placed them at a higher cognitive functioning level early in the morning due to increased attention and responsiveness, or if the teachers were morning types, which would have theoretically improved their teaching abilities due to their increased cognitive abilities as well. Due to this, it cannot be stated that earlier class times would improve all students' GPAs nor that it would improve an individual student's GPAs an equal amount.

As for time's effect on behavior, fewer behavioral incidents are reported during the morning, with the rate of incidents rising throughout the day and peaking just before children are released from school (Challen, 2016). This may be an important factor related to the results of the previous study where the morning courses received better grades than afternoon courses. Behavioral incidents were not taken into account when testing 


\section{The BRC Academy Journal of Education Vol. 8, No. 1}

for GPAs and it appears they may be correlated in some way to grades, with infractions sharing an inverse relationship with good marks. This may suggest that better grades are had when there are fewer social disturbances occurring, and may as well represent a shift in focus from school-related activities to social activities. Morningness/Eveningness were not tested for and therefore any correlations between behavioral incidents and morning/evening types were not recorded. It can be inferred from both studies that academically related task-oriented productivity is higher in the morning than it is in the afternoon or evening. To fill this gap, we took care to not only examine time of day affects and morningness/eveningness affects but examined their interaction. We expect that morning types will be more productive in the morning (9am-12 pm) and that evening types will be more productive in the evening (6pm-12am).

\section{Personality and Performance}

Other studies have explored the effect of another influential individual difference: personality. Previous research shows that personality is related to the quality of work produced and that it can even significantly affect academic performance in students (Sanches, Rejano, \& Rodriguez, 2001). Often considered the most influential and used commonly in studies of personality are the "Big-Five" personality traits, comprised of Neuroticism, Openness, Agreeableness, Extraversion, and Conscientiousness (Goldberg, 1990). Across multiple studies, results have concurrently suggested that individuals with high scores of conscientiousness have high productivity. Likewise, those scoring high on the neuroticism scale score low on productivity. (Cubel et al, 2016; Neal et al, 2012; Mishra \& Jha, 2015). These traits seem to not only dictate what personality types are most productive, but also under what circumstances various personality types perform the best (Barrick \& Mount, 1991). For example, individuals scoring high with openness work best and are most productive when alone. This suggests that the trait of openness inhibits cooperation. Individuals scoring high on extraversion, inversely, worked less proficiently 
while alone (Neal et al, 2012). These implications are significant when applied institutions. Students testing higher for openness may perform better academically if they are taught in smaller, more-personal groups and were assigned to complete work individually. Inversely, those testing high for extraversion may be placed in groups to learn and complete multi-person projects. The implications are that 1.) individual differences are important for understanding productivity, and 2.) the interaction between individual differences and the circumstances under which individuals work are also important for understanding productivity. In the next section, we discuss another important individual difference for productivity, morningness/eveningness, and its interaction with time of day.

\section{Morningness}

Individual differences play an integral part in individual productivity. Previous research (Escribano, Díaz-Morales, Delgado, \& Collado, 2012; Beşoluk, 2011; Mishra \& Jha, 2015) has explored the effect of a significantly influential individual difference: Morningness/Eveningness. Individual productivity fluctuates throughout the day. Studies suggest that this is due to the interaction between an individual's morningness (morning type/evening type) and the time of day it is. This has proved particularly relevant for students who, pre-secondary education, have academic schedules that start early in the day and end during the mid-to-late afternoon. Evening types have been found to have worse academic performance than Morning types on average (Escribano et al, 2012). This has been attributed to the fact that Morning types, when attending school, are learning at their peak-cognitive time range, while Evening types are learning at their lowest (Escribano et al, 2012). That is, morning types are completing work and learning the academic curriculum when they are more awake, alert, and primed to understand new information. For evening types, this period of alertness takes place after school has already been let out. This distinction has been particularly important during exams, nearly all of which take place during the morning. Morning 
types were found to perform significantly better on high school entrance exams that took place during morning hours, while evening types performed significantly worse (Beşoluk, 2011.) Contrary to both of these studies, Mishra \& Jha (2015) found that there was no significant effect of Morningness/Eveningness on the productivity of students. However, it should be noted that Mishra and Jha (2015) did not take into account the time of day the work was completed and therefore it is significantly different than the previous studies. It is quite possible that Morning types and Evening types have an equal level of productivity when the total work completed is tallied at the end of the day; the low productivity levels of morning individuals during evenings and the low productivity levels of evening individuals during mornings may result in equal overall productivity over the course of a day. In this instance, morning types may have completed their work in the morning and evening types in the evening. Time of day was not held constant, and therefore is not an accurate predictor of the correlation between Morningness and academic performance in highly structured institutions. In the current study, we test the specific interaction between time of day and morningness/eveningness. Furthermore, we divided the day into discrete time periods. Morning ranged from $9 \mathrm{am}$ to noon, early afternoon was from noon to $3 \mathrm{pm}$, late afternoon was from $3 \mathrm{pm}$ to $6 \mathrm{pm}$, evening was $6 \mathrm{pm}$ to $9 \mathrm{pm}$, and late evening was 9pm to midnight. We expect that there will be no overall difference in productivity among individuals varying on the morningness scale, but that morning types will be more productive in the morning (9am-12pm) and that evening types will be more productive in the evening (6pm-12am).

\section{This STUdy: Summary AND RESEARCH QUESTIONS}

As previously mentioned, while there is a great deal of literature analyzing the effect of various factors on individual productivity nearly all of these factors are tested independently of one another. The purpose of the current study is to measure these variables as well as their interactions 
to fill in any gaps left by previous research. We recruited undergraduate students to be tested for Morningness and to complete productivity surveys daily. These surveys were completed five times a day, one survey for each discrete time period (morning 9am-12pm, early afternoon 12pm-3pm, late afternoon 3pm-6pm, early evening 6pm-9pm, evening $9 \mathrm{pm}-12 \mathrm{am}$ ) for ten weekdays (Monday-Friday). In designing the study, we took extreme care to ask questions that would not only examine the main effects of morningness, the day of the week, and time of day but to also ask questions that would examine the interactions of these factors. We first hypothesize that Fridays and Mondays are the least productive days of the week due to low affective states coming social weekend activities. This has been unanimously supported across research, though the reasons for these effects has only been suggested and have not been studied in any refinement and therefore we explored the meanings behind these effects. Second, we hypothesized that morningness does not affect overall productivity. This was found in Mishra and Jha's (2015) study but refuted in others (Escribano et al, 2011). Finally, we hypothesize that morning types are more productive early in the day and evening types are more productive later in the day due to their independent peak cognitive abilities. It seems that there has been some discrepancy in the results of previous studies researching this particular topic and, while many assumptions were made, there were no studies testing evening type productivity during various periods of the day and specifically comparing it to morning type productivity during various periods of the day. Therefore, we compared time periods and morning/evening types as an interaction.

\section{Methods}

\section{Participants and Procedures}

Undergraduate students in Upstate New York were recruited to participate in the current study for extra credit. The study was approved by the 
46 The BRC Academy Journal of Education Vol. 8, No. 1

institution's internal review board (IRB), and participants were informed of their rights and the nature of the study and signed a copy of the consent form before participating.

\section{Limited Preview Complete}

This concludes the limited preview of this paper. Please purchase full access.

\section{Citation Information}

Kristin Lee Sotak, Tianna R. Moxley, Samira Todd, Shannon Yearwood, and Gregory J. Privitera. "Productivity: Time of Day, Day of week, and Morningness Effects." The BRC Academy fournal of Education 8, no. 1 (2020): 85-111. https://dx.doi.org/10.15239/j.brcacadje.2020.08.01.ja04

\section{Web Appendix}

A web appendix for this case is available at: https://dx.doi.org/10.15239/ j.brcacadje.2020.08.01.wa04 